based on the data provided by the fire department (ambulance transportation) and the medical institutions in some communities working on SC.

Results Although there are limitations to have the exact cost of the social loss under the different conditions in each community, in the case of community $\mathrm{A}$, one of the communities with longest experience of SC programs, we found that the community can save 18,081,333 USD (per 100,000) when they have zero suicide and depression.

Conclusion In this study, possible losses made from influence on their families and workplaces are not included to the calculation. With the consideration of those conditions, the social loss can be much higher. To see precise losses, in addition to direct losses, we should identify what make indirect influences on the social losses. and it can be different by different causes of injuries.

Learning Outcomes With the scandalized frame for the calculation of the social loss, we can show the benefits of prevention programs. It can convince policy makers to understand how much benefit the programs for injury prevention can make in their communities

\section{P1.005 ACTION PLAN FOR SAFETY, BASED ON LOCAL CONDITIONS, NATIONAL POLICIES, GLOBAL VISIONS}

Eva Vaagland*. Norwegian Safety Forum, Oslo, Norway

10.1136/injuryprev-2021-safety.32

Context Norwegian laws and regulations state that municipalities shall promote health and well-being, contribute to good environmental conditions and prevent mental and somatic illnesses and injuries. Preventive efforts are given broad attention.

This gives Norway a supportive framework for prevention, and a potential interest for safety work on community level. But public health work mainly focuses on lifestyle diseases and the prevention of these. Less effort is put into injury prevention and safety promotion. The Norwegian Safety Forum (NSF) is a non-profit organization, a national advocate for safety supported by the ministry of health. It's a a hub for information with activities, networking and meetings on the agenda. We want to engage local communities in safety promotion.

Process NSF has developed a national program for community safety based on local conditions, challenges and available resources, Norwegian laws and regulations, WHO visions, and Safe Community experiences. The program is developed to meet national targets and will guide municipalities to reach these goals by developing multisector collaboration and use documented prevention measures. NSF offers advice, guidance, tools, networks and seminars.

Outcome We have established a national network With about 40 municipalities using the program for community safety. The program is endorced by the National Program for Public Health, The National Program for Safe Elderly and the National Plan for Road Safety. The model with a step-by-step approach is a useful instrument for communities, turning global visions and national policies into local realities.

\section{A - Child - Road, March 23, 2021}

\section{A.001 ROAD TRAFFIC INJURIES AMONG CHILDREN AND ADULTS IN THE REPUBLIC OF MOLDOVA}

Angela Cazacu-Stratu, Svetlana Cociu*. Department of Hygiene 'Nicolae Testemitanu' State University of Medicine and Pharmacy, Republic of Moldova, Chisinau, Moldova (the Republic of)

\subsection{6/injuryprev-2021-safety.33}

Background Road accidents are a major problem for public health and a major cause of deaths and injuries worldwide. In the Republic of Moldova, road accidents are one of the mortality cause among children aged between 14-18 years old and one of the main causes of morbidity of children aged between $0-14$ years old. The aim of this study was to underline the particularities of road injuries and to develop effective preventive measures of reducing road injures.

Methods A retrospective study was performed with data collection from the official statistical reports of the Chisinau Police Department for 2010-2018, SPSS was used for data analysis.

Results Road injuries account for $1.2 \%$ of the total number of child injuries in the country and $1.4 \%$ in Chisinau. Mortality from road trauma in the country during the last 8 years registered the highest level in September (13.5\%) and June (11\%) and the fewest deaths were detected in March - 3.4\%, while in Chisinau, most deaths were registered in January, August and November (19.1\% each). In $46.2 \%$ of children were as a pedestrian. Men aged 20-29 years old and 50-59 years old were identified at higher risk of dying being a driver or being a passenger in a transport unit.

Conclusion Data showed a downward trend of $30.3 \%$, although it is necessary to strengthen the cross-sectoral actions and take common efforts in road safety.

Learning Outcomes Our results suggested the need for health promotion and health education campaigns and intersectoral approach among the vulnerable groups.

\section{A.002 CHILD SAFEGUARDING - IT'S A JOURNEY NOT A DESTINATION \\ ${ }^{1,2}$ Alan Foster* . 'City of Casey, Australia; ${ }^{2}$ Narre Warren, Australia}

10.1136/injuryprev-2021-safety.34

Background/Aims The City of Casey wanted to be aspirational and not just compliant when implementing the Victorian Child Safe Standards and Reportable Conduct Scheme.

Methods Council set out to embed a child safe culture throughout the organisation that would:

- demonstrate a zero-tolerance approach towards child abuse,

- ensure children and young people who engage with City of Casey services are safe and feel empowered to seek support,

- equip staff and volunteers to recognise the signs of child abuse and manage reportable incidents effectively and in compliance with legislation; and

- develop and maintain a robust governance framework. 
Results Since the project began it has:

- consulted with staff, parents and young people to better inform practical implementation of the Standards,

- developed an internal online and face to face training program which has been rolled out to more than 2,263 internal stakeholders,

- developed and implemented a centralised reporting and investigation procedure managed by an Internal Response Team,

- developed Council's Child Safety Policy;

- drafted a Child Safe Procedural Guide to operationalise Council's commitment to keep children and young people safe.

Conclusions Child safeguarding is now an integral part of our organisational strategy.

Council has transparent governance arrangements in place including accessible child safeguarding policies and procedures, a code of conduct, a risk management framework, and clear accountabilities for staff of all levels.

In addition, Casey is committed to continuous improvement and learning from incidents, identified risks and ongoing activities that engage children and young people with Council and in their safety and wellbeing.

\section{A.003 POTENTIAL CRASH-RISKS FOR VEHICLES IN STAGGERED CAR-FOLLOWING ON MULTILANE-HIGHWAYS UNDER LOW-DENSITY CONDITIONS}

Kar Pranab*, PadinjareVenthuruthiyil Suvin, Chunchu Mallikarjuna. Indian Institute of Technology, Guwahati, India

\subsection{6/injuryprev-2021-safety.35}

The challenges associated with evaluating the traffic flow quality on multilane highways are manifold. Better quality of driving is achieved when mobility and safety are optimally tradedoff. The majority of the studies on Level of Service (LOS) have primarily focused on the improvement of travel time, or travel speed by minimizing the travel delay. However, the safety aspect/risk-taking behavior of drivers remains ignored. Rear-end crashes are the most frequently occurring one that accounts for about $29 \%$ of all the crashes and resulting in a significant number of injuries and fatalities each year. The presence of slow-moving vehicles in highspeed highways would lead to car-following situations even in lower density conditions, which impart potential crash risks. The current study evaluates the risky behavior of drivers by identifying the potential conflict between the leading and lagging vehicles. The study performs both macroscopic and microscopic diagnosis with the help of detailed trajectory as well as detector data. We analyzed the variability in both speed and acceleration characteristics of drivers corresponding to a potential conflict scenario. The conflict points were identified by using the surrogate safety measures termed Time-to-Collision (TTC) and Stopping-Sight-Distance (SSD). Results indicate that even under low-density conditions, the potential risk of rear-end crash is high due to the presence of significant slow-moving vehicles. The acceleration characteristics indicate that many drivers accept potentially risky maneuvers under the presence of slowmoving vehicle ahead. The crash potential due to such a situation could be minimized by regulating the designated lanes for slow-moving vehicles.

\section{A.004 BUILD CONFIDENCE AMONG POLICY-DECISION MAKERS BY REMOVING CONCERNS FOR CSR LAW IMPLEMENTATION}

Cui MinYan(Monica)*, Chunyan(Amidy) Peng* . Safe Kids China, Shanghai, China

10.1136/injuryprev-2021-safety.36

Background No national law mandating child restraint systems (CRS) is in China. Shanghai passed traffic rules in 2017 requiring the use of CRS, but with no penalties. Implementation is weak due to significant government concerns. Using research and marketing data, Safe Kids China (SKC) developed targeted activities to remove the concerns of the policymakers to promote CRS implementation.

Objective Implementation of the law on CRS in Shanghai traffic rules.

Method SKC allayed concerns among decisionmakers by: 1) Highlighting the importance of CRS law, sharing global experience, and providing technical support to stakeholders via seminars; 2) Presenting parents' support for CRS and data on increasing CRS purchasing trends, and assisting new parents' CRS usage at hospitals; 3) Training certified child passenger safety technicians (CPST) involving police and healthcare staff. Results Shanghai decision-makers submitted a policy proposal to strengthen CRS implementation. The related government agencies include CRS education into their work. Police have included CRS into their training. The police coordinated other agencies' resources for the public education. Five policemen were trained as child passenger safety techinician (CPST) and 12 policemen received CRS training. The CDC distributed posters to 1600 kindergartens. Police conduct CRS checks. However, penalties are not to be issued for CRS violations.

Conclusion In March 2017, Shanghai issued the amended traffic rules, including a provision that children under 4 riding in a family car must use CRS. However, continuous promotion and political buy-in is required to have more strict rules on CRS.

\section{B - Drowning - Factors, March 23, 2021}

\section{A.001 FATAL DROWNING IN WHO REGION OF THE AMERICA'S - A LEADING KILLER}

Stephen Beerman*. 'University of British Columbia, Faculty of Medicine, Dept of Family Practice, Nanaimo, Canada; ${ }^{2}$ Canadian Drowning Prevention Coalition, Fredericton, Canada

\subsection{6/injuryprev-2021-safety.37}

Background Drowning is a serious, preventable and neglected public health issue resulting an estimated 295,210 death per year, worldwide. An estimated 1 Billion people live in the WHO Region of the Americas/Pan American Health Organization (PAHO) in 53 countries and territories. There is an estimated 23,096 drowning deaths per year based on GBD 2017 data.

The PAHO works with countries to improve and protect health. PAHO engages in technical cooperation with member countries. The PAHO does not have a program for Drowning Prevention.

Methods Using PAHO website Leading Causes of Death data, to focus on the ranking of drowning as a leading causes of death. The last 5 years of available data in all age groups, were reviewed 